\title{
Morroniside protects against cerebral ischemia/reperfusion injury by inhibiting neuron apoptosis and MMP2/9 expression
}

\author{
GUOYONG ZENG ${ }^{1}$, WEIJIANG DING ${ }^{2}$, YIN LI $^{2}$, MEIYING SUN ${ }^{3}$ and LIYING DENG ${ }^{2}$ \\ ${ }^{1}$ Department of Neurology, The Affiliated Ganzhou Hospital of Nanchang University, Ganzhou, Jiangxi 341000; \\ ${ }^{2}$ Department of Neurology, The Second Affiliated Hospital of Nanchang University, Nanchang, Jiangxi 330006; \\ ${ }^{3}$ Department of Neurology, The People's Hospital of Fuzhou, Fuzhou, Jiangxi 344000, P.R. China
}

Received November 3, 2017; Accepted March 9, 2018

DOI: $10.3892 /$ etm.2018.6457

\begin{abstract}
The aim of the present study was to investigate the effect of morroniside against matrix metalloproteinase (MMP)2/9 and focal cerebral ischemia/reperfusion (I/R) injury in rats. A rat model of focal cerebral $I / R$ injury rats was established and rats were administered with 30,90 or $270 \mathrm{mg} / \mathrm{kg} / \mathrm{day}$ morroniside for 7 days. The expression of MMP2/9 and neuronal apoptosis were assessed. In addition, the expression of active caspase-3, B-cell lymphoma 2 (Bcl-2) and Bcl-2-associated X protein (Bax) were measured. The results revealed that MMP2 and MMP9 expression was upregulated and the percentage of apoptotic neurons was increased in rats with focal cerebral I/R injury compared with the control. However, treatment with morroniside significantly inhibited I/R-induced MMP2/9 expression and neuron apoptosis compared with the untreated I/R injury group. Morroniside administration also decreased the expression of active caspase-3 and increased the Bcl-2/Bax ratio compared with untreated rats with focal cerebral I/R injury. The inhibitory effect of morroniside on MMP2/9 expression and neuron apoptosis was dose dependent. In summary, the results of the present study suggest that morroniside is able to protect against cerebral I/R injury in the brain and may have potential as a therapeutic treatment for patients who have suffered a stroke.
\end{abstract}

\section{Introduction}

Ischemia/reperfusion (I/R) causes severe damage to vital organs, including the brain, heart, lungs and kidneys (1-4). I/R injury encompasses stroke, which is characterized by a sudden

Correspondence to: Dr Liying Deng, Department of Neurology, The Second Affiliated Hospital of Nanchang University, 1 Minde Road, Nanchang, Jiangxi 330006, P.R. China

E-mail: dengliying_1@tom.com

Key words: morroniside, cerebral ischemia/reperfusion injury, matrix metalloproteinase-2, matrix metalloproteinase-9 focal or global neurological impairment and is one of the most prevalent causes of mortality and disability worldwide (5-7).

In principle, cerebral ischemia is caused by cerebral blood flow reduction leading to a series of pathological changes, including ionic homeostasis loss, energy failure, increased oxidative stress, apoptosis, irreversible tissue/organ damage and neurological and behavioral deficits $(8,9)$. I/R injury-induced damage is associated with dysregulation of complex interactions, inflammatory responses and extracellular matrix (ECM) remodeling (10). The ECM forms a key component of the basement membrane, and is essential for the permeability and integrity of blood-brain barrier (BBB), while matrix metalloproteinases (MMPs) can exert proteolytic activity to degrade all ECM components $(1,11)$.

Abnormal degradation of ECM components in rats with cerebral I/R injury reduces the integrity and permeability of the $\mathrm{BBB}$, which may lead to leakage of fluids from the blood to the brain and subsequent brain edema (1). Type IV collagen is a key component of the ECM complex and a major proteolytic substrate of MMP2 and MMP9 (1). Overexpression of MMP2 and MMP9 has previously been reported in I/R injured tissues, including the heart, liver and kidneys $(1,3,12)$. Furthermore, breakdown of the BBB in rats may be induced by upregulated proteolytic activity of MMP2 and MMP9, which subsequently results in over-degradation of type IV collagen to reduce BBB integrity and promote BBB permeability (1).

At present, typical pharmacological agents used to treat cerebral I/R injury therapy are neuroprotective, antioxidative, antiapoptotic or anti-inflammatory agents $(13,14)$. Previous studies have reported the protective effect of morroniside, an active extract of Cornus officinalis, against neuronal apoptosis, oxidative stress and inflammation (8,15-17). Furthermore, the neuroprotective effect of morroniside has been reported in rats with focal cerebral ischemia (8). However, to the best of our knowledge, the effect of morroniside on MMP2/9 expression and neuron apoptosis in cerebral I/R injury has yet to be reported.

The aim of the present study was to elucidate the effect of morroniside on MMP2/9 expression and neuron apoptosis in rats with cerebral I/R injury. Rats with focal cerebral I/R injury were administrated with morroniside $(30,90$ and $270 \mathrm{mg} / \mathrm{kg}$ ) for 7 days, following which MMP2/9 expression and neuronal apoptosis were detected and comparatively analyzed. 


\section{Materials and methods}

Animal model and treatment. A total of 50 adult male Sprague Dawley rats (age, 7-8 weeks; weight, 260-280 g) were purchased from Beijing Vital River Laboratory Animal Technology Co., Ltd. (Beijing, China). All rats were housed at $25 \pm 2{ }^{\circ} \mathrm{C}$ and $50 \%$ humidity, with a 12 -h light/dark cycle, and food and water ad libitum. Ethical approval was granted by the Medical Ethics Committee of the Affiliated Ganzhou Hospital of Nanchang University (Nanchang, China).

Rats were randomly assigned into five groups ( $\mathrm{n}=10$ in each). Rats in the control group underwent sham surgery. All other rats underwent suture-occluded surgery as described by Longa et al (18), with a $0.26 \mathrm{~mm}$ nylon monofilament (Beijing Shandong Biotech Co., Ltd., Beijing, China) inserted through the right common carotid artery and were divided into groups as follows: The cerebral I/R injury model group (model), no treatment; low dose group, $30 \mathrm{mg} / \mathrm{kg} / \mathrm{day}$ morroniside (Sinopharm Chemical Reagent Co., Ltd., Shanghai, China) by gavage; moderate dose group, $90 \mathrm{mg} / \mathrm{kg} /$ day morroniside by gavage; high dose group, $270 \mathrm{mg} / \mathrm{kg} /$ day morroniside by gavage. Rats in the control and model groups received an equal volume of normal saline. Longa's five-grade scale methods were used to score neurological deficit following surgery (18) and rats with a score of 0 or 4 were excluded from the current study.

Immunofluorescence assay. Following 7 days of morroniside treatment, rats were anesthetized intravenously (30 mg/kg 5\% pentobarbital sodium; Sigma Aldrich; Merck KGaA, Darmstadt, Germany) and brains were harvested. Brain tissues were mounted in optimal cutting temperature medium (Sakura Finetek USA, Inc., Torrance, CA, USA), frozen at $-20^{\circ} \mathrm{C}$ in a Leica cryostat device (Leica Microsystems $\mathrm{GmbH}$, Wetzlar, Germany) and cut into $4-\mu \mathrm{m}$ sections. Sections were treated with $3 \% \mathrm{H}_{2} \mathrm{O}_{2}$ solutions for $20 \mathrm{~min}$ at $37^{\circ} \mathrm{C}$, blocked with normal goat serum (Sigma Aldrich; Merck $\mathrm{KGaA}$ ) for $30 \mathrm{~min}$ at $37^{\circ} \mathrm{C}$, and incubated with anti-MMP2 (cat. no. sc-13594) and anti-MMP9 (cat. no. sc-21733; 1:200; Santa Cruz Biotechnology, Inc., Dallas, TX, USA) antibodies at $4^{\circ} \mathrm{C}$ for $20 \mathrm{~h}$. Sections were subsequently incubated with $\mathrm{Cy} 3^{\circledR}$-labelled goat anti-mouse immunoglobulin (Ig)G (cat. no. ab97035; 1:100; Abcam, Cambridge, MA, USA) in the dark at $37^{\circ} \mathrm{C}$ for $2 \mathrm{~h}$. DAPI solution was used for nuclear staining at $37^{\circ} \mathrm{C}$ for $10 \mathrm{~min}$. Slides were observed using a fluorescence microscope (magnification, x200) and assessed using Image-Pro Plus 6 software (Media Cybernetics, Inc., Rockville, MD USA).

Apoptotic cell analysis. Apoptotic cells in brain tissues were detected using a TUNEL assay. Briefly, ischemic penumbra cortex area was resected and the frozen sections (4- $\mu$ m-thick) were fixed using $4 \%$ polyoxymethylene at room temperature for $20 \mathrm{~min}$. and and a colorimetric TUNEL kit (EMD Millipore, Billerica, MA, USA) was used according to the manufacturer's protocol for in situ apoptosis detection. The sections were washed by PBS and then incubated with prepared TUNEL solution for $1 \mathrm{~h}$ at $37^{\circ} \mathrm{C}$ in a dark chamber. A $50 \mu \mathrm{l}$ DAB solution $\left(2.5 \mu \mathrm{l} \mathrm{DAB}, 0.5 \mu 130 \% \mathrm{H}_{2} \mathrm{O}_{2}\right.$ and $\left.47 \mu \mathrm{l} \mathrm{PBS}\right)$ was added for nuclear staining at $37^{\circ} \mathrm{C}$ for $20 \mathrm{~min}$. The TUNEL-positive cells were observed and counted under a light microscope at a magnification of $\mathrm{x} 200$. Apoptotic cells were stained brown and the mean was calculated from 10 independent fields.

Western blotting. Brain tissues were homogenized and lysed in radioimmunoprecipitation assay buffer (Sigma Aldrich; Merck $\mathrm{KGaA})$. Proteins were quantified using BCA method and equal amounts $(50 \mu \mathrm{g})$ were separated by $8 \%$ SDS-PAGE. Proteins were transferred to a polyvinylidene fluoride membrane, blocked with $5 \%$ non-fat milk at $37^{\circ} \mathrm{C}$ for $1 \mathrm{~h}$, and then was subsequently incubated with specific primary antibodies against MMP2 (cat. no. sc-13594), MMP9 (cat. no. sc-21733), active Caspase-3 (cat. no. sc-56052), B-cell lymphoma 2 (Bcl-2; cat. no. sc-56015) and Bcl-2-associated X protein (Bax; cat. no. sc-70407) and GAPDH (cat. no. sc-47724; all 1:1,000; Santa Cruz Biotechnology, Inc.) at $4^{\circ} \mathrm{C}$ overnight. The membrane was incubated with horseradish peroxidase-conjugated goat anti-rabbit IgG (cat. no. sc-2004; 1:1,000, Santa Cruz Biotechnology, Inc.) for $2 \mathrm{~h}$ at $37^{\circ} \mathrm{C}$ followed by enhanced chemilluminescence reagents (GE Healthcare Life Sciences, Little Chalfont, UK). Quantity One 4.4.1 software (Bio-Rad Laboratories, Inc., Hercules, CA, USA) was used to quantify bands with GAPDH as an internal control.

Reverse transcription-quantitative polymerase chain reaction $(R T-q P C R)$. RT-qPCR was performed to measure the relative expression of MMP2 and MMP9 mRNA. Total RNA was extracted from brain tissues using TRIzol (Invitrogen; Thermo Fisher Scientific, Inc., Waltham, MA, USA) and RT was performed to synthesize cDNA. RNA was converted into cDNA using a High Capacity cDNA Reverse Transcription kit (Applied Biosystems; Thermo Fisher Scientific, Inc.) according to the manufacturer's protocol. MMP2 and MMP9 mRNA expression was detected on an ABI 7500 fast real time PCR platform (Applied Biosystems; Thermo Fisher Scientific, Inc.) using a SYBR Premix Ex Taq ${ }^{\mathrm{TM}}$ kit (Takara Bio, Inc., Otsu, Japan) and the following primers: MMP2, forward 5'-CTGGGC CACGCCATCGCTGC-3 and reverse 5'-GCTTGCGGGGAA AGAAGTTG-3'; MMP9, forward 5'-GGCAGCCCCTGCTCC TGGTG-3' and reverse 5'-CCTTTAGTGTCTCGCTGTCC-3'; GAPDH, forward 5'-CTCCTCCTGGCCTCGCTGT-3' and reverse 5'-GCTGTCACCTTCACCGTTCC-3'. Temperature protocols were as follows: $95^{\circ} \mathrm{C}$ for $4 \mathrm{~min}$ followed by 40 cycles of $95^{\circ} \mathrm{C}$ for $30 \mathrm{sec}, 60^{\circ} \mathrm{C}$ for $35 \mathrm{sec}$ and $72^{\circ} \mathrm{C}$ for $20 \mathrm{sec}$ and a final extension step at $65^{\circ} \mathrm{C}$ for $6 \mathrm{~min}$. The relative mRNA expression level was analyzed using the $2^{-\Delta \Delta C q}$ method with GAPDH as the internal reference gene (19). Each reaction was run in triplicate.

Statistical analysis. All data are expressed as the mean \pm standard error of the mean. SPSS 17.0 software was used for statistical analyses (SPSS, Inc., Chicago, IL, USA). One-way analysis of variance followed by Scheffe's test was used to assess differences between groups. $\mathrm{P}<0.05$ was considered to indicate a statistically significant difference.

\section{Results}

Morroniside reduces the expression of MMP2 and MMP9 in an $I / R$ injury model. The results of western blotting and RT-qPCR revealed that MMP2 and MMP9 protein (Fig. 1A) 

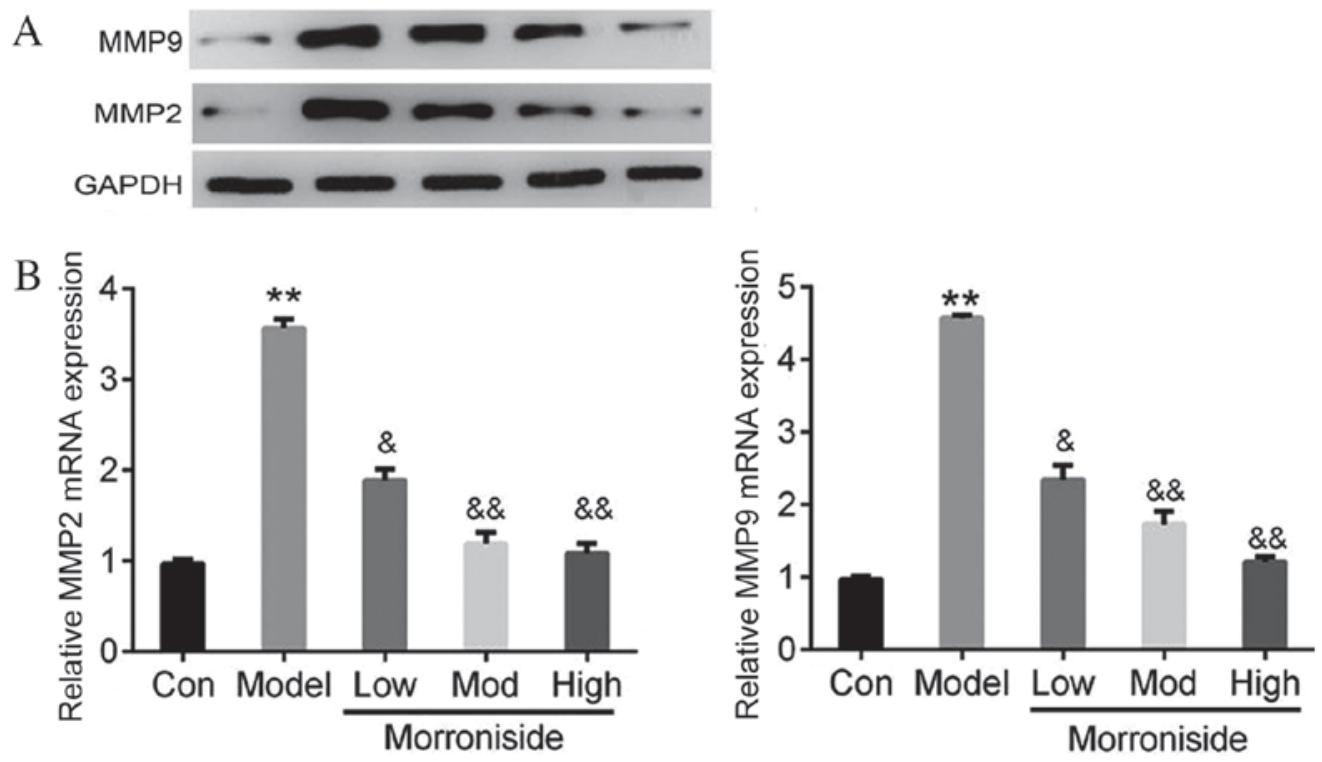

Figure 1. Western blotting and reverse transcription-quantitative polymerase chain reaction were performed to measure MMP2 and MMP9 (A) protein and (B) mRNA, respectively, in rat brain tissues $(\mathrm{n}=10) .{ }^{* * *} \mathrm{P}<0.01$ vs. Con, ${ }^{\&} \mathrm{P}<0.05$ an ${ }^{\&}{ }^{\&} \mathrm{P}<0.01$ vs. Model. MMP, matrix metalloproteinase; Con, control; Low, $30 \mathrm{mg} / \mathrm{kg}$ morroniside; Mod, $90 \mathrm{mg} / \mathrm{kg}$ morroniside; High, $270 \mathrm{mg} / \mathrm{kg}$ morroniside.
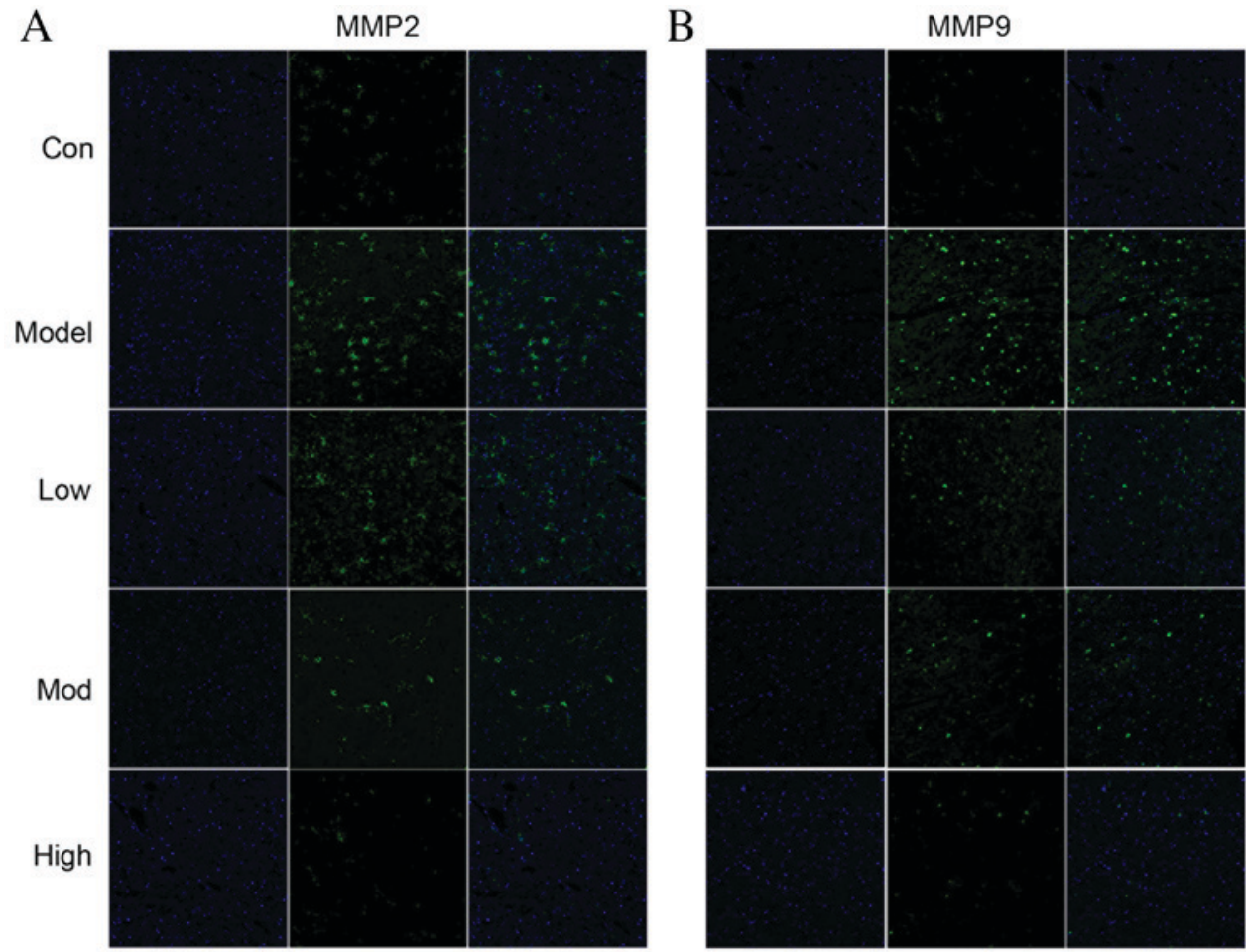

Figure 2. An immunofluorescence assay was performed to assess the expression of (A) MMP2 and (B) MMP9 in rat brain tissues ( $\mathrm{n}=10$ ). Magnification, $\mathrm{x} 200$. MMP, matrix metalloproteinase; Con, control; Low, 30 mg/kg morroniside; Mod, 90 mg/kg morroniside; High, 270 mg/kg morroniside.

and mRNA $(\mathrm{P}<0.01$; Fig. 1B) expression was increased in the model group compared with the control group. However, treatment with morroniside reduced the expression of MMP2 and MMP9 mRNA (Fig. 1A) and protein (low dose, $\mathrm{P}<0.05$; moderate and high doses, $\mathrm{P}<0.01$; Fig. $1 \mathrm{~B}$ ) in a dose dependent manner compared with the model group. Immunofluorescence results revealed that the pattern of MMP2 and MMP9 positive cells in cortical infarctions followed a similar trend to protein expression (Fig. 2). The MMP2 and MMP9 fluorescence intensity in the brains of rats was increased in the model group compared with the control (Fig. 2). However, treatment with morroniside markedly reduced MMP2 and MMP9 fluorescence compared with the model group (Fig. 2).

Morroniside inhibits neuron apoptosis. Apoptotic neurons on the sections from ischemic penumbra cortex were detected using a TUNEL assay. The percentage of apoptotic neurons was significantly increased in the model group compared 
A
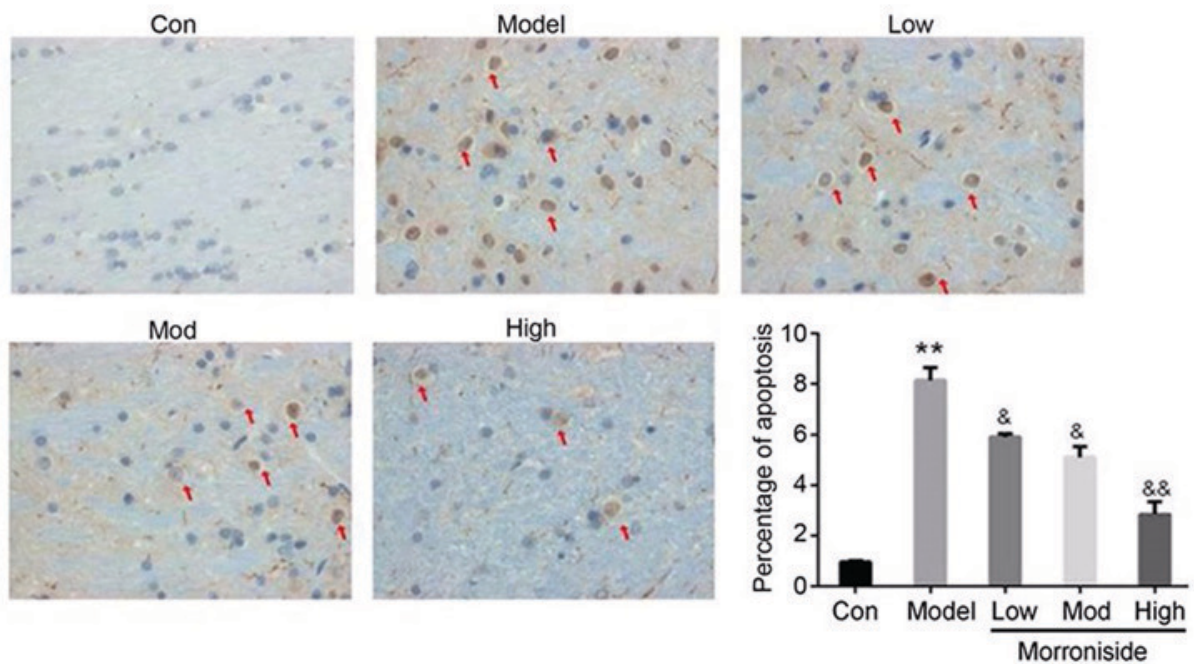

B
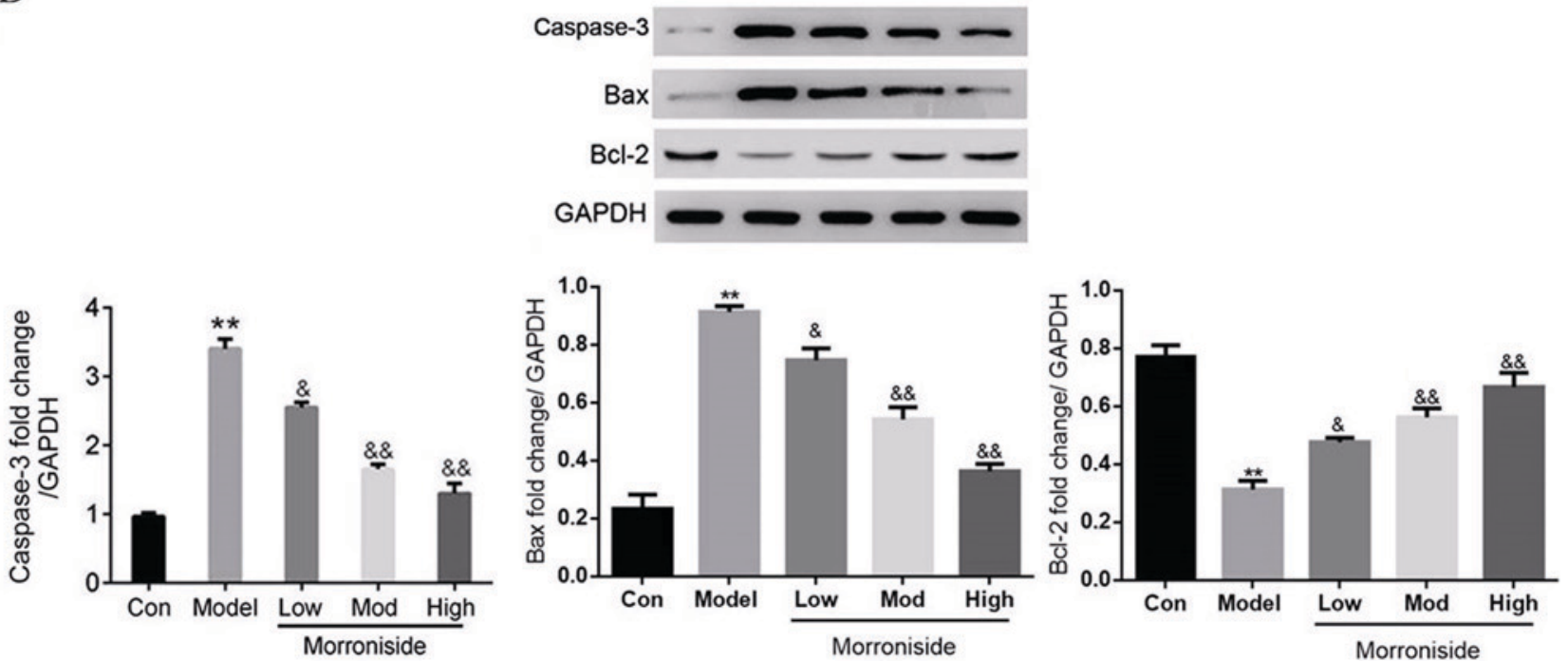

Figure 3. (A) A TUNEL assay was performed to quantify apoptotic neurons in a cerebral ischemia/reperfusion injury model (n=10 rats). (B) Western blotting was performed to measure the expression of active caspase-3, Bcl-2 and Bax protein. Magnification, $\mathrm{x} 200 .{ }^{* *} \mathrm{P}<0.01$ vs. Con, ${ }^{\text {\& }} \mathrm{P}<0.05$ an ${ }^{\text {\& }} \mathrm{P}<0.01$ vs. Model. Bcl-2, B-cell lymphoma 2; Bax, Bcl-2-associated X protein; Con, control; Low, $30 \mathrm{mg} / \mathrm{kg}$ morroniside; Mod, $90 \mathrm{mg} / \mathrm{kg} \mathrm{morroniside;} \mathrm{High,} 270 \mathrm{mg} / \mathrm{kg}$ morroniside.

with the control $(\mathrm{P}<0.01$; Fig. 3A). However, treatment with morroniside significantly reduced I/R-associated neuron apoptosis in a dose dependent manner (low and moderate doses, $\mathrm{P}<0.05$; high dose, $\mathrm{P}<0.01$; Fig. $3 \mathrm{~A}$ ). The expression of apoptosis-associated proteins was assessed using western blotting. The results demonstrated that active caspase-3 and Bax were significantly upregulated in the model group compared with the control group $(\mathrm{P}<0.01$; Fig. $3 \mathrm{~B})$, while $\mathrm{Bcl}-2$ was significantly downregulated $(\mathrm{P}<0.01$; Fig. $3 \mathrm{~B})$. The expression of active caspase- 3 and Bax was significantly downregulated by morroniside treatment in a dose-dependent manner (low dose, $\mathrm{P}<0.05$; moderate and high doses, $\mathrm{P}<0.01$; Fig. $3 \mathrm{~B}$ ), while the expression of Bcl-2 was significantly upregulated (low dose, $\mathrm{P}<0.05$; moderate and high doses, $\mathrm{P}<0.01$; Fig. 3B).

\section{Discussion}

The upregulation of MMPs, in particular MMP2 and MMP9, results in the degradation of type IV collagen, which in turn impairs BBB integrity and enhances $\mathrm{I} / \mathrm{R}$ injuries in the brain (1). The present study is the first to demonstrate the effect of morroniside treatment on MMP2/9 expression and neuron apoptosis and in $\mathrm{I} / \mathrm{R}$. The results revealed that MMP2 and MMP9 are upregulated in the brains of rats with cerebral I/R injury, whereas the administration of morroniside significantly ameliorated this effect. These results suggest that morroniside may convey a protective effect in the brains of rats with I/R injury.

Increased MMP2 and MMP9 expression has been reported in I/R injuries of the lung, heart, skeletal muscle, kidneys and other organs (1-4). Previous studies have revealed that MMP2/9 overexpression disrupts the BBB and results in edema $(20,21)$. It has also been reported that the inhibition of MMP2/9 may protect against cerebral ischemia and improve organ function $(12,22-25)$. However, MMP2 knockout does not protect against acute focal ischemia injury in brain (26). Kato et al (10) demonstrated that MMP2 deletion was able to impair poly ADP-ribose polymerase 1 
degradation, enhance MMP9 activity and exacerbate hepatic $\mathrm{I} / \mathrm{R}$ injury in mice (10). It has also been reported that whereas MMP9 deficiency may protect against hepatic I/R injury (12). Together, these reports suggest that effect of MMP2/9 in I/R injury is complex and, while MMP2/9 inhibition may be beneficial, it is not necessarily required to improve I/R injury. However, the results of the present study demonstrated that morroniside administration inhibits MMP2 and MMP9 in $\mathrm{I} / \mathrm{R}$ injured brains, revealing morroniside was beneficial to protect against cerebral I/R injury.

The results of the present study revealed that morroniside significantly reduces the percentage of apoptotic neurons, inhibits caspase- 3 activation and increases the $\mathrm{Bcl}-2 / \mathrm{Bax}$ protein ratio in rats with cerebral $\mathrm{I} / \mathrm{R}$ injury. Cerebral I/R injury results in neurological and behavioral deficits, which are accompanied by neuron apoptosis $(9,27,28)$. Wang et al $(16)$ reported that morroniside was able to reduce $\mathrm{H}_{2} \mathrm{O}_{2}$-induced SH-SY5Y cell apoptosis, intracellular $\mathrm{Ca}^{2+}$ accumulation and mitochondrial membrane potential, while also inhibiting the $\mathrm{H}_{2} \mathrm{O}_{2}$-induced decrease in superoxide dismutase activity (16). The protective effect of morroniside on cell apoptosis and other diseases has been widely reported $(8,29,30)$. The results of the present study suggest that morroniside treatment has a protective effect against I/R-induced neuron apoptosis; future studies should investigate the effect of MMP2 or MMP9 in rats with I/R injury to confirm the mechanisms of morroniside.

In conclusion, the present study revealed that protective effect of morroniside in rats with cerebral I/R injury. Morroniside inhibits the I/R-induced upregulation of MMP2/9 and neuron apoptosis, suggesting that morroniside may promote behavioral deficit repair following cerebral I/R injury. However, the underlying mechanism responsible for these effects remains to be elucidated.

\section{Acknowledgements}

Not applicable.

\section{Funding}

No funding was received.

\section{Availability of data and materials}

The datasets used and/or analyzed during the current study are available from the corresponding author on reasonable request.

\section{Authors' contributions}

GZ wrote the manuscript and conducted the majority of the experiments. WD, YL and MS collected and analyzed the data. LD designed the study and approved the manuscript for submission.

\section{Ethics approval and consent to participate}

Ethical approval was granted by the Medical Ethics Committee of the Affiliated Ganzhou Hospital of Nanchang University (Nanchang, China).

\section{Consent for publication}

Not applicable.

\section{Competing interests}

All of the authors have no conflict of interest in this research.

\section{References}

1. Roach DM, Fitridge RA, Laws PE, Millard SH, Varelias A and Cowled PA: Up-regulation of MMP-2 and MMP-9 leads to degradation of type IV collagen during skeletal muscle reperfusion injury; protection by the MMP inhibitor, doxycycline. Eur J Vasc Endovasc Surg 23: 260-269, 2002.

2. Yano M, Omoto Y, Yamakawa Y, Nakashima Y, Kiriyama M, Saito Y and Fujii Y: Increased matrix metalloproteinase 9 activity and mRNA expression in lung ischemia-reperfusion injury. J Heart Lung Transplant 20: 679-686, 2001.

3. Cheung PY, Sawicki G, Wozniak M, Wang W, Radomski MW and Schulz R: Matrix metalloproteinase-2 contributes to ischemia-reperfusion injury in the heart. Circulation 101: 1833-1839, 2000.

4. Zhang X, Sakamoto T, Hata Y, Kubota T, Hisatomi T, Murata T, Ishibashi $\mathrm{T}$ and Inomata $\mathrm{H}$ : Expression of matrix metalloproteinases and their inhibitors in experimental retinal ischemia-reperfusion injury in rats. Exp Eye Res 74: 577-584, 2002.

5. Navarro-Sobrino $\mathrm{M}$, Rosell A, Hernández-Guillamon $\mathrm{M}$, Penalba A, Boada C, Domingues-Montanari S, Ribó M, Alvarez-Sabín J and Montaner J: A large screening of angiogenesis biomarkers and their association with neurological outcome after ischemic stroke. Atherosclerosis 216: 205-211, 2011.

6. Feigin VL, Forouzanfar MH, Krishnamurthi R, Mensah GA, Connor M, Bennett DA, Moran AE, Sacco RL, Anderson L, Truelsen T, et al: Global and regional burden of stroke during 1990-2010: Findings from the Global burden of disease study 2010. Lancet 383: 245-254, 2014.

7. Chen L, Xiang Y, Kong L, Zhang X, Sun B, Wei X and Liu H: Hydroxysafflor yellow A protects against cerebral ischemia-reperfusion injury by anti-apoptotic effect through PI3K/Akt/GSK3 $\beta$ pathway in rat. Neurochem Res 38: 2268-2275, 2013.

8. Wang W, Xu J, Li L, Wang P, Ji X, Ai H, Zhang L and Li L: Neuroprotective effect of morroniside on focal cerebral ischemia in rats. Brain Res Bull 83: 196-201, 2010.

9. Wang Q, Sun AY, Simonyi A, Jensen MD, Shelat PB, Rottinghaus GE, MacDonald RS, Miller DK, Lubahn DE, Weisman GA and Sun GY: Neuroprotective mechanisms of curcumin against cerebral ischemia-induced neuronal apoptosis and behavioral deficits. J Neurosci Res 82: 138-148, 2005.

10. Kato H, Duarte S, Liu D, Busuttil RW and Coito AJ: Matrix metalloproteinase-2 (MMP-2) gene deletion enhances MMP-9 activity, impairs PARP-1 degradation, and exacerbates hepatic ischemia and reperfusion injury in mice. PLoS One 10: e0137642, 2015.

11. Rosenberg GA, Estrada E, Kelley RO and Kornfeld M: Bacterial collagenase disrupts extracellular matrix and opens blood-brain barrier in rat. Neurosci Lett 160: 117-119, 1993.

12. Hamada T, Fondevila C, Busuttil RW and Coito AJ: Metalloproteinase-9 deficiency protects against hepatic ischemia/reperfusion injury. Hepatology 47: 186-198, 2008.

13. Ai J, Wan H, Shu M, Zhou H, Zhao T, Fu W and He Y: Guhong injection protects against focal cerebral ischemia-reperfusion injury via anti-inflammatory effects in rats. Arch Pharm Res 40: 610-622, 2017.

14. Zhao P, Zhou R, Zhu XY, Hao YJ, Li N, Wang J, Niu Y, Sun T, Li YX and Yu JQ: Matrine attenuates focal cerebral ischemic injury by improving antioxidant activity and inhibiting apoptosis in mice. Int J Mol Med 36: 633-644, 2015.

15. Xu HQ, Hao HP, Zhang X and Pan Y: Morroniside protects cultured human umbilical vein endothelial cells from damage by high ambient glucose. Acta Pharmacol Sin 25: 412-415, 2004.

16. Wang W, Sun F, An Y, Ai H, Zhang L, Huang W and Li L: Morroniside protects human neuroblastoma SH-SY5Y cells against hydrogen peroxide-induced cytotoxicity. Eur J Pharmacol 613: 19-23, 2009. 
17. Park CH, Noh JS, Kim JH, Tanaka T, Zhao Q, Matsumoto K, Shibahara $\mathrm{N}$ and Yokozawa T: Evaluation of morroniside, iridoid glycoside from Corni Fructus, on diabetes-induced alterations such as oxidative stress, inflammation, and apoptosis in the liver of type 2 diabetic db/db mice. Biol Pharm Bull 34: 1559-1565, 2011.

18. Longa EZ, Weinstein PR, Carlson S and Cummins R: Reversible middle cerebral artery occlusion without craniectomy in rats. Stroke 20: 84-91, 1989.

19. Livak KJ and Schmittgen TD: Analysis of relative gene expression data using real-time quantitative PCR and the 2(-Delta Delta C(T)) method. Methods 25: 402-408, 2001.

20. Pérez-Hernández M, Fernández-Valle ME, Rubio-Araiz A, Vidal R, Gutiérrez-López MD, O'shea E and Colado MI 3,4-Methylenedioxymethamphetamine (MDMA, ecstasy) produces edema due to BBB disruption induced by MMP-9 activation in rat hippocampus. Neuropharmacology 118: 157-166, 2017.

21. Tasaki A, Shimizu F, Sano Y, Fujisawa M, Takahashi T, Haruki H, Abe M, Koga M and Kanda T: Autocrine MMP-2/9 secretion increases the BBB permeability in neuromyelitis optica. J Neurol Neurosurg Psychiatry 85: 419-430, 2014.

22. Lin HB, Cadete VJ, Sra B, Sawicka J, Chen Z, Bekar LK, Cayabyab F and Sawicki G: Inhibition of MMP-2 expression with siRNA increases baseline cardiomyocyte contractility and protects against simulated ischemic reperfusion injury. Biomed Res Int 2014: 810371, 2014

23. Yan P, Chen KJ, Wu J, Sun L, Sung HW, Weisel RD, Xie J and Li RK: The use of MMP2 antibody-conjugated cationic microbubble to target the ischemic myocardium, enhance Timp3 gene transfection and improve cardiac function. Biomaterials 35 : 1063-1073, 2014.

24. Lin H, Sra B, Cadete VJ, Sawicka J, Cayabyab FS and Sawicki G: 774 MMP-2 siRNA Protects Against Contractile Dysfunction in Cardiomyocytes Subjected to Ischemia/Reperfusion. Canadian J Cardiology 28: S396-S397, 2012.
25. Zhang HT, Zhang P, Gao Y, Li CL, Wang HJ, Chen LC, Feng Y, Li RY, Li YL and Jiang CL: Early VEGF inhibition attenuates blood-brain barrier disruption in ischemic rat brains by regulating the expression of MMPs. Mol Med Rep 15: 57-64, 2017.

26. Asahi M, Sumii T, Fini ME, Itohara S and Lo EH: Matrix metalloproteinase 2 gene knockout has no effect on acute brain injury after focal ischemia. Neuroreport 12: 3003-3007, 2001.

27. Hua F, Ma J, Ha T, Xia Y, Kelley J, Williams DL, Kao RL, Browder IW, Schweitzer JB, Kalbfleisch JH and Li C: Activation of toll-like receptor 4 signaling contributes to hippocampal neuronal death following global cerebral ischemia/reperfusion. J Neuroimmunol 190: 101-111, 2007.

28. Liang K, Ye Y, Wang Y, Zhang J and Li C: Formononetin mediates neuroprotection against cerebral ischemia/reperfusion in rats via downregulation of the $\mathrm{Bax} / \mathrm{Bcl}-2$ ratio and upregulation PI3K/Akt signaling pathway. J Neurol Sci 344: 100-104, 2014

29. Wang W, Huang W, Li L, Ai H, Sun F, Liu C and An Y: Morroniside prevents peroxide-induced apoptosis by induction of endogenous glutathione in human neuroblastoma cells. Cell Mol Neurobiol 28: 293-305, 2008.

30. Yokozawa T, Yamabe N, Kim HY, Kang KS, Hur JM, Park CH and Tanaka T: Protective effects of morroniside isolated from Corni Fructus against renal damage in streptozotocin-induced diabetic rats. Biol Pharm Bull 31: 1422-1428, 2008.

This work is licensed under a Creative Commons Attribution-NonCommercial-NoDerivatives 4.0 International (CC BY-NC-ND 4.0) License. 